\title{
Melatonin protects MG63 osteoblast-like cells from hydrogen peroxide-induced cytotoxicity by maintaining mitochondrial function
}

\author{
FEI SHE ${ }^{1}$, WENBO WANG $^{2}$, YAN WANG $^{1}$, PEIFU TANG $^{1}$, JUNQIANG WEI ${ }^{1}$, \\ HUA CHEN $^{1}$ and BOXUN ZHANG ${ }^{1}$ \\ Departments of ${ }^{1}$ Orthopaedic Surgery and ${ }^{2}$ Endocrinology, General Hospital of the \\ Chinese People's Liberation Army, Beijing 100853, P.R. China
}

Received March 21, 2013; Accepted November 18, 2013

DOI: $10.3892 / \mathrm{mmr} .2013 .1832$

\begin{abstract}
Osteoporosis is a bone disease that has been connected with reactive oxygen species (ROS)-induced cytotoxicity. Mitochondrial dysfunction may be involved in the mechanism underlying ROS-induced cytotoxicity. It has been demonstrated that melatonin may exert cytoprotective effects by improving mitochondrial energetics and functions in several models of oxidative damage. In the present study, the MG63 osteoblast-like cell line was exposed to different concentrations of hydrogen peroxide $\left(\mathrm{H}_{2} \mathrm{O}_{2} ; 0,100,200,400\right.$ or $\left.800 \mu \mathrm{M}\right)$ for $8 \mathrm{~h}$, and 200 or $400 \mu \mathrm{M} \mathrm{H}_{2} \mathrm{O}_{2}$ for various periods of time $(0.5$, 4,8 or 12 h). Results showed that $\mathrm{H}_{2} \mathrm{O}_{2}$ significantly reduced cell viability, increased the release of lactate dehydrogenase, increased the levels of ROS and malondialdehyde, reduced the concentration of adenosine-5'-triphosphate, disrupted the mitochondrial membrane potential $(\Delta \Psi \mathrm{m})$ and decreased the mitochondrial DNA copy number in MG63 cells. However, pretreatment with melatonin effectively decreased all of these $\mathrm{H}_{2} \mathrm{O}_{2}$-induced changes in cytotoxicity and mitochondrial dysfunction in MG63 cells. The protective effects of melatonin may be attributed to its ability to maintain mitochondrial function in $\mathrm{H}_{2} \mathrm{O}_{2}$-treated cells. This study suggests that melatonin is a potential pharmacological agent for preventing ROS-induced bone loss in diseases such as osteoporosis.
\end{abstract}

\section{Introduction}

Osteoporosis is a systemic skeletal disease characterized by low bone mineral density and micro-architectural

Correspondence to: Professor Hua Chen or Professor Boxun Zhang, Department of Orthopaedic Surgery, General Hospital of the Chinese People's Liberation Army, 28 Fuxing Road, Beijing 100853, P.R. China

E-mail: 157776860@qq.com

E-mail: 940114371@qq.com

Key words: mitochondrial dysfunction, melatonin, hydrogen peroxide, cytotoxicity deterioration of bone, leading to increased bone fragility and susceptibility to fractures (1). The clinical complications of osteoporosis include pain, fractures and disability. Recently, osteoporosis has become a predominant public health problem in elderly individuals, particularly in postmenopausal females (2). Reactive oxygen species (ROS) such as superoxide anions, hydroxyl radicals and hydrogen peroxide $\left(\mathrm{H}_{2} \mathrm{O}_{2}\right)$ lead to severe damage to DNA, protein and lipids. Therefore, ROS is a predominant cause of cell damage and death in numerous pathological conditions (3). Furthermore, it has been demonstrated that ROS-induced bone cell cytotoxicity is critical in the development of osteoporosis (4). Under normal physiological and pathological conditions, the mitochondria are the predominant producers of ROS, such as hydrogen peroxide, hydroxyl radicals, superoxide radicals and singlet oxygen (5). Additionally, the mitochondria are the key targets of ROS-mediated damage (6). It has been shown that mitochondrial dysfunction is involved in ROS-induced bone cell cytotoxicity $(2,7)$. Therefore, it is plausible that therapeutic strategies which aim to prevent or delay ROS-induced bone cell cytotoxicity by maintaining mitochondrial function may be suitable for the prevention or treatment of bone loss-related disorders.

Melatonin is an indoleamine primarily secreted by the pineal gland and is also synthesized in other organs, such as the skin (8), gastrointestinal tract (9), thymus (10), retina (11) and bone marrow (12). Melatonin is involved in the regulation of several physiological processes such as sleep-wake rhythms $(13,14)$, regulation of the circadian cycle $(15,16)$, seasonal control of reproductive processes (17) and immune processes (18). In addition to these physiological actions, melatonin is a potent scavenger of ROS, such as the carbonate radical (19), which is presumed to be involved in mitochondrial damage (20). Furthermore, melatonin easily enters the mitochondria and exerts a direct beneficial effect on the maintenance of mitochondrial homeostasis (21). It has also been demonstrated that melatonin stabilizes the mitochondrial inner membrane, improves electron transport chain activity, increases ATP synthesis and protects mitochondrial DNA from oxidative damage (22-25). Based on the mitochondrial dysfunction observed during ROS-induced bone 
cell cytotoxicity and the beneficial effects of melatonin on the mitochondria, melatonin may be a useful molecule for preventing or treating diseases related to bone loss.

The aim of the present study was to investigate the potential efficacy of melatonin in the protection against ROS-induced bone cell cytotoxicity. To address this issue, the MG63 osteoblastic cell line was exposed to different concentrations of $\mathrm{H}_{2} \mathrm{O}_{2}$. As expected, melatonin pretreatment successfully attenuated $\mathrm{H}_{2} \mathrm{O}_{2}$-induced cytotoxicity in MG63 cells. The protective effects of melatonin were correlated with its ability to reduce oxidative damage, increase ATP production, maintain the mitochondrial membrane potential and preserve mitochondrial DNA content in $\mathrm{H}_{2} \mathrm{O}_{2}$-treated cells. This study suggests that melatonin effectively protects against $\mathrm{H}_{2} \mathrm{O}_{2}$-induced cytotoxicity in MG63 osteoblastic cells by maintaining mitochondrial function.

\section{Materials and methods}

Chemicals. $\mathrm{H}_{2} \mathrm{O}_{2}$ was purchased from Sigma-Aldrich (St. Louis, MO, USA). Melatonin was obtained from Sangon Biotech Co., Ltd. (Shanghai, China). The cell lysis buffer and bicinchoninic acid (BCA) protein assay kit were purchased from Beyotime (Shanghai, China).

Cell culture and treatments. MG63 osteoblast-like cells (American Type Culture Collection, Manassas, VA, USA) were cultured in Dulbecco's modified Eagle's medium (DMEM; Hyclone, Logan, UT, USA) supplemented with $10 \%$ heat-inactivated fetal bovine serum (FBS; HyClone) and $80 \mu \mathrm{g} / \mathrm{ml}$ penicillin/streptomycin (Sigma-Aldrich) in a $5 \% \mathrm{CO}_{2}$-humidified atmosphere at $37^{\circ} \mathrm{C}$. To estimate the toxicity of $\mathrm{H}_{2} \mathrm{O}_{2}$, MG63 cells were seeded at a density of $1 \times 10^{4}$ cells/well in 96-well plates, cultured overnight and then exposed to various concentrations of $\mathrm{H}_{2} \mathrm{O}_{2}(0,200,400$ or $800 \mu \mathrm{M}$ ) for $8 \mathrm{~h}$, or exposed to 200 or $400 \mu \mathrm{M} \mathrm{H}_{2} \mathrm{O}_{2}$ for different periods of time $(0.5,4,8$ and $12 \mathrm{~h})$. In other assays unless otherwise stated, the cells were seeded at a density of $2 \times 10^{5} /$ well in 6 -well plates, cultured overnight, pretreated with melatonin $(1 \mathrm{mM})$ for $2 \mathrm{~h}$ and then exposed to $\mathrm{H}_{2} \mathrm{O}_{2}(200$ or $400 \mu \mathrm{M})$ for $8 \mathrm{~h}$.

Measurement of cell viability and lactate dehydrogenase $(L D H)$ release. The viability of MG63 cells was assessed using the Cell Counting kit-8 (CCK-8; Dojindo, Kumamoto, Japan) according to the manufacturer's instructions. Following treatment with $\mathrm{H}_{2} \mathrm{O}_{2}$, the cells were cultured in $100 \mu \mathrm{l}$ fresh growth medium supplemented with $10 \mu \mathrm{l}$ CCK-8-solution for $2 \mathrm{~h}$ at $37^{\circ} \mathrm{C}$ and the absorption values were measured at $450 \mathrm{~nm}$ using a microplate reader. Cell viability was expressed as a percentage of untreated control cells (set at 100\%). All the experiments were performed in triplicate and were repeated three times.

LDH release was measured using the Cytotoxicity Detection kit (Roche, Mannheim, Germany) according to the manufacturer's instructions. The cells were pretreated with melatonin and exposed to $\mathrm{H}_{2} \mathrm{O}_{2}$ in a low-serum (1\% FBS) medium, in order to minimize the effects of $\mathrm{LDH}$ in the serum. Following treatment, cell-free culture supernatants were collected and incubated with $\mathrm{LDH}$ assay solution at $25^{\circ} \mathrm{C}$ for $30 \mathrm{~min}$. The optical density values were analyzed at $490 \mathrm{~nm}$ by subtracting the reference value at $620 \mathrm{~nm}$. The experiment was repeated three times and the results were expressed as a percentage of the maximum LDH release, obtained by lysing the cells in $1 \%$ Triton X-100.

Measurement of ROS and MDA levels. Intracellular ROS generation was detected by flow cytometry (BD FACSCanto II; BD Biosciences, Mississauga, ON, Canada) using 2',7'-dichlorofluoresceindiacetate (DCFH-DA; Beyotime, Shanghai, China). Subsequent to the indicated treatments, the cells were trypsinized, centrifuged and washed with fresh preheated DMEM to remove any $\mathrm{H}_{2} \mathrm{O}_{2}$ remaining at the end of the exposure time. The cells were then resuspended in preheated serum-free medium supplemented with DCFH-DA and incubated at $37^{\circ} \mathrm{C}$ for $20 \mathrm{~min}$. Following three washes with PBS, the fluorescence intensity of the cells in each group was measured by flow cytometry. The level of ROS is expressed as the mean of the DCF fluorescence intensity in each group. The experiment was performed in triplicate and repeated three times.

Intracellular malondialdehyde (MDA) levels were measured using a Lipid Peroxidation MDA assay kit (Beyotime) according to the manufacturer's instructions. Following $\mathrm{H}_{2} \mathrm{O}_{2}$ treatment, the cells were collected, lysed with cell lysis buffer and centrifuged. The supernatants were reacted with thiobarbituric acid (TBA) and the absorption values of the reaction products were measured with a microplate reader (Varioskan $^{\text {TM }}$ Flash 3001; Thermo Scientific, Waltham, MA, USA) at $535 \mathrm{~nm}$. The protein concentration was measured by the Bradford Protein assay. The experiment was repeated three times and the MDA levels were expressed as nmol/mg protein.

Measurement of ATP content. The ATP determination kit (Beyotime, Nanjing, China) was used to determine the ATP content. Following the termination of the treatment period, the cells were incubated with cell lysis buffer and centrifuged. The supernatants $(10 \mu \mathrm{l})$ were mixed with reaction buffer $(100 \mu \mathrm{l})$ and measured using a luminometer (Turner Designs Inc., Sunnyvale, CA, USA) and the experiments were repeated four times. The cellular ATP content was determined from an ATP standard curve and the results were expressed as a percentage, assuming that the ATP content of untreated control cells was $100 \%$.

Measurement of mitochondrial membrane potential. The mitochondrial membrane potential $(\Delta \Psi \mathrm{m})$ of MG63 cells was determined by the fluorescent, lipophilic and cationic probe, JC-1, according to the manufacturer's instructions. Briefly, the cells were seeded at a density of $1 \times 10^{4}$ cells/well in 96-well plates. Subsequent to the indicated treatments, the cells were incubated with $1 \mathrm{X} \mathrm{JC}-1$ in growth medium at $37^{\circ} \mathrm{C}$ for $20 \mathrm{~min}$ and then rinsed twice with JC-1 washing buffer. The green fluorescence intensities from the JC-1 monomer (with a $530-\mathrm{nm}$ excitation) and the red fluorescence intensities from the aggregated form of JC-1 (with a 590-nm emission) in the cells were measured by spectrofluorometry (FACSCalibur; Becton-Dickinson, Franklin Lakes, NJ, USA). The $\Delta \Psi \mathrm{m}$ of MG63 cells in each group was calculated as the fluorescence ratio of red to green. The experiment was repeated at least three times. 

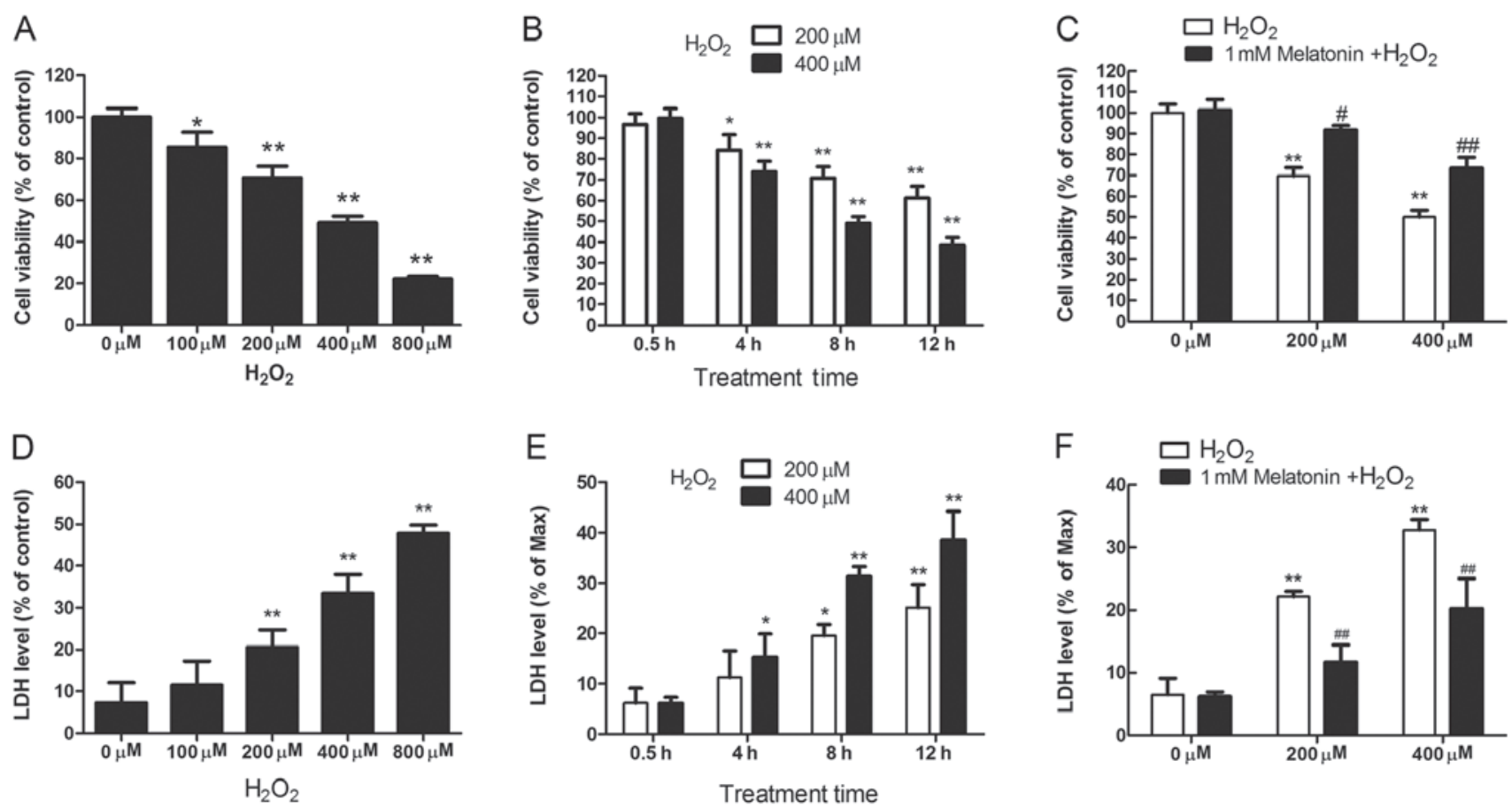

Figure 1. Protective effect of melatonin against hydrogen peroxide $\left(\mathrm{H}_{2} \mathrm{O}_{2}\right)$-induced cytotoxicity. (A) Cell viability and (D) lactate dehydrogenase (LDH) release in MG63 cells cultured in the absence or presence of $\mathrm{H}_{2} \mathrm{O}_{2}(100,200,400$ or $800 \mu \mathrm{M}$ ) for 8 h. Time course analyses of (B) cell viability and (E) LDH release for MG63 cells cultured with $\mathrm{H}_{2} \mathrm{O}_{2}(200$ or $400 \mu \mathrm{M})$ for $0.5,4,8$ or $12 \mathrm{~h}$. (C) Cell viability and (F) LDH release of MG63 cells pretreated with melatonin $(1 \mathrm{mM})$ for $2 \mathrm{~h}$ and exposed to $\mathrm{H}_{2} \mathrm{O}_{2}(200$ or $400 \mu \mathrm{M})$ for $8 \mathrm{~h}$. Values are presented as the mean $\pm \mathrm{SD}$ of three independent experiments; ${ }^{*} \mathrm{P}<0.05$ and ${ }^{* * *} \mathrm{P}<0.01$ vs. sham-exposed control group; ${ }^{\#} \mathrm{P}<0.05$ and ${ }^{\# \#} \mathrm{P}<0.01$ vs. groups treated with $\mathrm{H}_{2} \mathrm{O}_{2}$ at the same concentration.

Measurement of mitochondrial DNA (mtDNA) copy number. qPCR was used to determine the mtDNA copy number, and was conducted using the Mx3000p Real-Time PCR detection system (Stratagen Inc., La Jolla, CA, USA) with the SYBR-Green I detection method. Total DNA was extracted from the treated cells using a DNA extract kit (Omega Bio-Tek, Norcross, GA, USA). The mtDNA copy number was expressed relative to the nuclear DNA copy number. Two different segments of mtDNA were amplified: cytochrome coxidase subunit I (COX I), encoded by the heavy chain of mtDNA, and NADH dehydrogenase subunit 6 (ND6), encoded by the light chain of mtDNA. The nuclear amplicon was generated by amplification of glyceraldehyde 3-phosphate dehydrogenase (GAPDH), which was chosen as an internal standard. The primers for mtDNA were: Sense: 5'-CATCGGGGTAGTCCGAGTAA-3' and antisense: 5'-ACGTTGTAGCCCACTTCCAC-3' for COXI; sense: 5'-TGATTGTTAGCGGTGTGGTC-3' and antisense: 5'-CCACAGCACCAATCCTACCT-3' for ND6; and sense: 5'-TCAGTGGTGGACCTGACCTG-3' and antisense: 5'-TGCTGTAGCCAAATTCGTTG-3' for GAPDH. Each measurement was performed in triplicate, repeated at least three times and normalized against control cells.

Statistical analysis. Experimental data are presented as the mean \pm SD. Each experiment was repeated at least three times. Differences between two groups were analyzed using the Student's t-test. Multiple comparisons were analyzed by analysis of variance and Tukey's post hoc tests. $\mathrm{P}<0.05$ was considered to indicate a statistically significant difference. Images are representative of three or more experiments.

\section{Results}

Melatonin reduces the cytotoxicity of $\mathrm{H}_{2} \mathrm{O}_{2}$ in $\mathrm{MG63}$ cells. The cytotoxicity of $\mathrm{H}_{2} \mathrm{O}_{2}$ in MG63 cells was analyzed by assaying cell viability and measuring LDH release. The viability of MG63 cells exposed to $\mathrm{H}_{2} \mathrm{O}_{2}$ was reduced significantly in a dose- and time-dependent manner (Fig. $1 \mathrm{~A}$ and B). Additionally, $\mathrm{H}_{2} \mathrm{O}_{2}$ treatment resulted in a dose- and time-dependent increase in LDH release by MG63 cells (Fig. 1D and E). $\mathrm{H}_{2} \mathrm{O}_{2}$ (200 and $400 \mu \mathrm{M}$ ) induced significant toxicity in MG63 cells after $8 \mathrm{~h}$ of treatment; therefore, these treatment conditions were used for subsequent experiments. Melatonin pretreatment $(1 \mathrm{mM})$ significantly prevented the loss of cell viability and reduced LDH release in $\mathrm{H}_{2} \mathrm{O}_{2}$-treated MG63 cells (Fig. 1C and F), demonstrating that melatonin protected against the cytotoxic effects of $\mathrm{H}_{2} \mathrm{O}_{2}$ in MG63 cells.

Melatonin ameliorates $\mathrm{H}_{2} \mathrm{O}_{2}$-mediated oxidative stress in MG63 cells. The levels of intracellular ROS in MG63 cells following $\mathrm{H}_{2} \mathrm{O}_{2}$ treatment were measured by flow cytometry using the fluorescent probe DCFH-DA. ROS generation increased significantly in MG63 cells exposed to $\mathrm{H}_{2} \mathrm{O}_{2}$ (Fig. 2A and B). Furthermore, to investigate the effects of $\mathrm{H}_{2} \mathrm{O}_{2}$ on oxidative damage, the intracellular levels of MDA (a marker of lipid peroxidation) were measured. The concentration of MDA increased from $1.49 \mathrm{nmol} / \mathrm{mg}$ protein in untreated control cells to 2.78 and $3.54 \mathrm{nmol} / \mathrm{mg}$ protein in 200 and $400 \mu \mathrm{M} \mathrm{H}_{2} \mathrm{O}_{2}$-treated cells, respectively (Fig. 2C). However, melatonin pretreatment $(1 \mathrm{mM})$ successfully attenuated the $\mathrm{H}_{2} \mathrm{O}_{2}$-induced increases in ROS release and intracellular MDA levels in MG63 cells (Fig. 2). 
A
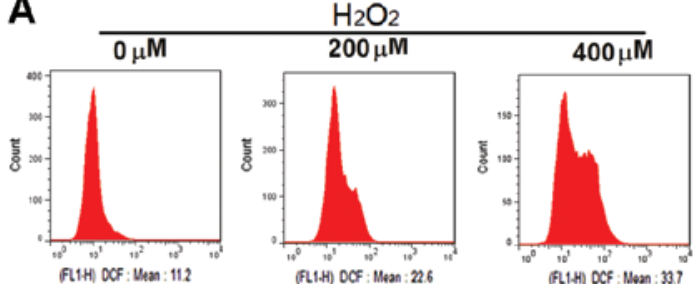

$1 \mathrm{mM}$ Melatonin $+\mathrm{H}_{2} \mathrm{O}_{2}$

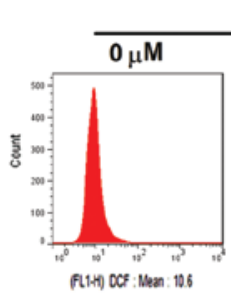

$200 \mu \mathrm{M}$
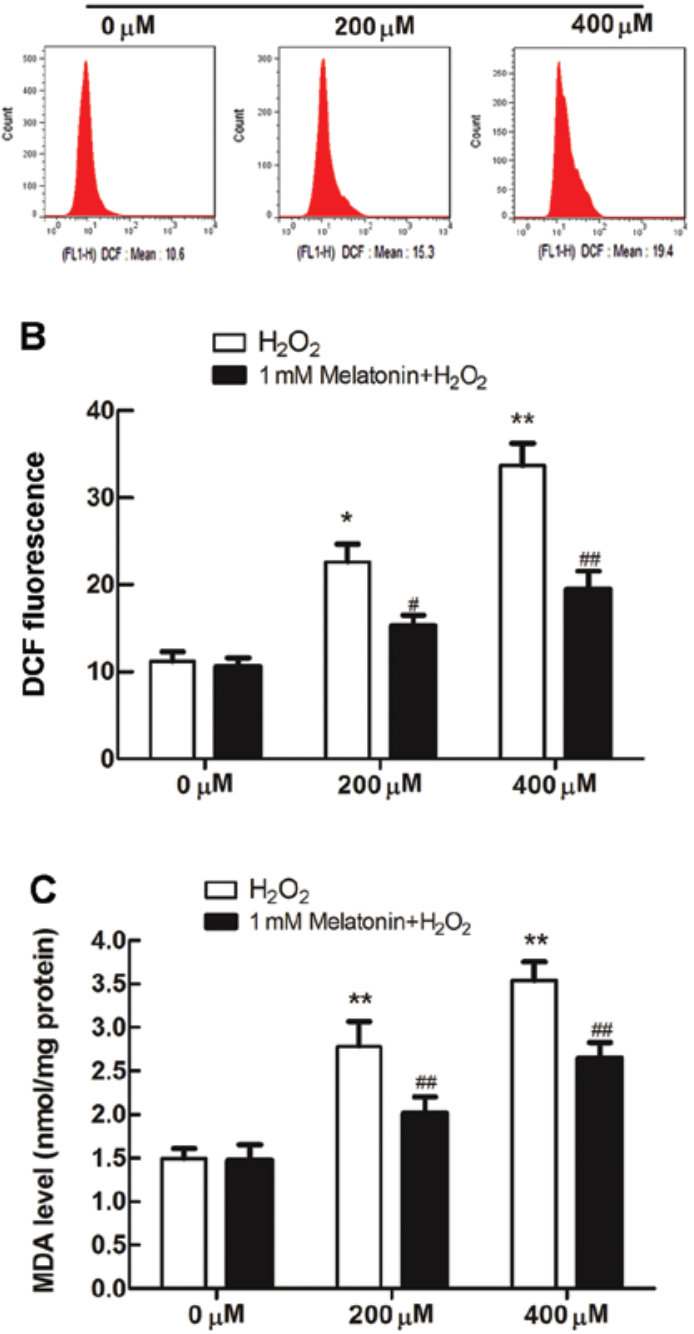

Figure 2. Effects of melatonin on reactive oxygen species (ROS) generation and lipid oxidation in hydrogen peroxide $\left(\mathrm{H}_{2} \mathrm{O}_{2}\right)$-treated cells. Following pretreatment with melatonin $(1 \mathrm{mM})$ for $2 \mathrm{~h}$, the cells were treated with $\mathrm{H}_{2} \mathrm{O}_{2}(200$ or $400 \mu \mathrm{M})$ for $8 \mathrm{~h}$. The treated cells were washed with fresh preheated Dulbecco's modified Eagle's medium to remove any remaining $\mathrm{H}_{2} \mathrm{O}_{2}$ at the end of the exposure time. Subsequent to this the levels of intracellular ROS in different groups of cells were measured by flow cytometry with 2',7'-dichlorofluoresceindiacetate (DCFH-DA). (A) Representative flow cytometric images of intracellular ROS levels. (B) Quantitative analysis of ROS, the level of intracellular ROS is expressed as the mean of DCF fluorescence intensity. (C) Cellular malondialdehyde (MDA) levels were measured using the thiobarbituric acid method and the levels of MDA were expressed as $\mathrm{nmol} / \mathrm{mg}$ protein. Values are presented as the mean $\pm \mathrm{SD}$ of three independent experiments. ${ }^{*} \mathrm{P}<0.05$ and ${ }^{*} \mathrm{P}<0.01$ vs. sham-exposed control group; ${ }^{\#} \mathrm{P}<0.05$ and ${ }^{\# \#} \mathrm{P}<0.01$ vs. groups treated with $\mathrm{H}_{2} \mathrm{O}_{2}$ at the same concentration.

Melatonin maintains the ATP content in MG63 cells exposed to $\mathrm{H}_{2} \mathrm{O}_{2}$. The protective effects of melatonin on respiratory function were evaluated by measuring the ATP concentrations in MG63 cells exposed to $\mathrm{H}_{2} \mathrm{O}_{2}$ following pretreatment

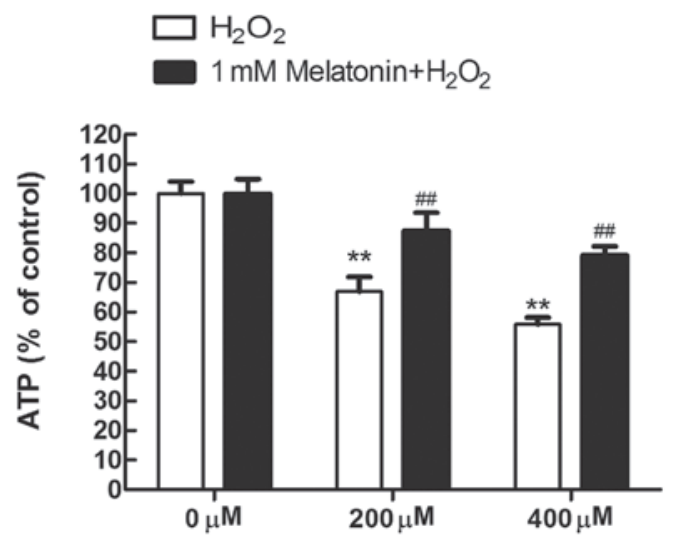

Figure 3. Effects of melatonin on the adenosine-5'-triphosphate (ATP) content in hydrogen peroxide $\left(\mathrm{H}_{2} \mathrm{O}_{2}\right)$-treated cells. Following pretreatment with melatonin $(1 \mathrm{mM})$ for $2 \mathrm{~h}$, cells were treated with $\mathrm{H}_{2} \mathrm{O}_{2}(200$ or $400 \mu \mathrm{M})$ for $8 \mathrm{~h}$. ATP concentrations were determined using an ATP determination kit and expressed as a percentage of the sham-exposed control group. Values are presented as the mean $\pm \mathrm{SD}$ of three independent experiments; ${ }^{* *} \mathrm{P}<0.01$ vs. sham-exposed control group and ${ }^{\# \#} \mathrm{P}<0.01$ vs. groups treated with the same concentration of $\mathrm{H}_{2} \mathrm{O}_{2}$.

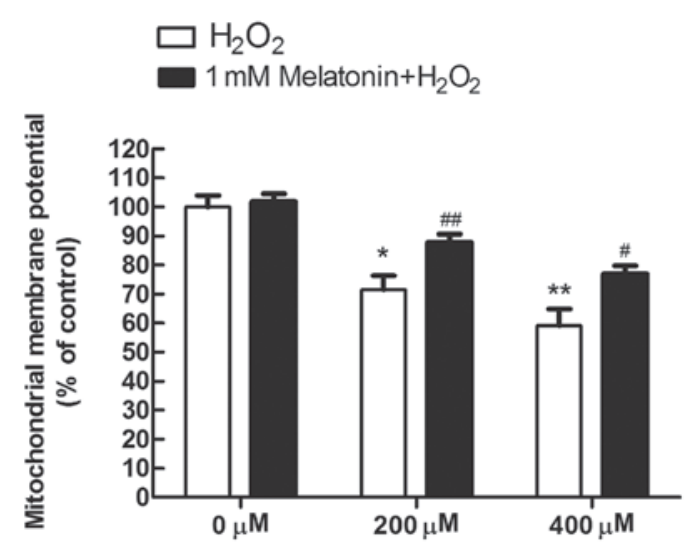

Figure 4. Effects of melatonin on the mitochondrial membrane potential in hydrogen peroxide $\left(\mathrm{H}_{2} \mathrm{O}_{2}\right)$-treated cells. Following pretreatment with melatonin $(1 \mathrm{mM})$ for $2 \mathrm{~h}$, cells were exposed to $\mathrm{H}_{2} \mathrm{O}_{2}(200$ and $400 \mu \mathrm{M})$ for $8 \mathrm{~h}$. The mitochondrial membrane potential of the cells was detected by using the fluorescent, lipophilic and cationic probe, JC-1. The mitochondrial membrane potential of MG63 cells in each group was calculated as the fluorescence ratio of red to green. The values are expressed as a percentage of the sham-exposed control group and are presented as the mean \pm SD for three independent experiments. ${ }^{*} \mathrm{P}<0.05$ and ${ }^{* *} \mathrm{P}<0.01$ vs. sham-exposed control group; ${ }^{*} \mathrm{P}<0.05$ and ${ }^{\# \#} \mathrm{P}<0.01$ vs. groups treated with $\mathrm{H}_{2} \mathrm{O}_{2}$ at the same concentration.

with melatonin. Compared with the untreated control group, the ATP concentrations were significantly reduced in the $\mathrm{H}_{2} \mathrm{O}_{2}$-treated groups (all $\mathrm{P}<0.05$ ). However, pretreatment with melatonin maintained the ATP content in MG63 cells exposed to $\mathrm{H}_{2} \mathrm{O}_{2}$ (Fig. 3).

Melatonin prevents the loss of mitochondrial membrane potential in MG63 cells exposed to $\mathrm{H}_{2} \mathrm{O}_{2}$. To analyze whether the inhibition of mitochondrial disruption is a mechanism underlying the protective effects of melatonin, the fluorescence probe JC-1 was used to estimate the mitochondrial membrane potential $(\Delta \Psi \mathrm{m})$, which is a sensitive indicator of the mitochondrial integrity and bioenergetic function. As a result, it was demonstrated that exposure to 200 and $400 \mu \mathrm{M}$ 
A
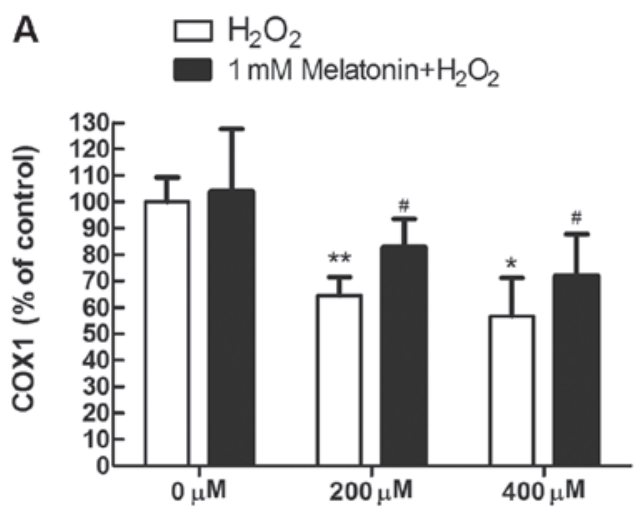

B
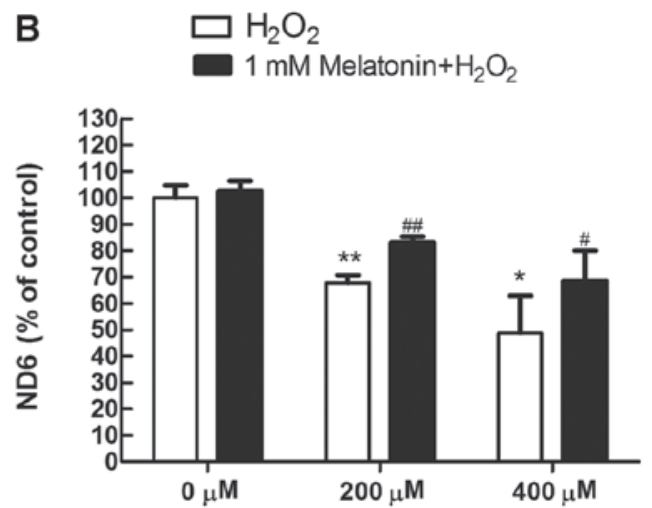

Figure 5. Effects of melatonin on mitochondrial DNA (mtDNA) copy numbers in hydrogen peroxide $\left(\mathrm{H}_{2} \mathrm{O}_{2}\right)$-treated cells. Following pretreatment with melatonin $(1 \mathrm{mM})$ for $2 \mathrm{~h}$, cells were treated with $\mathrm{H}_{2} \mathrm{O}_{2}(200$ or $400 \mu \mathrm{M})$ for $8 \mathrm{~h}$. mtDNA copy number was measured by qPCR. Two specific fragments of mtDNA were amplified: (A) cytochrome coxidase subunit I (COX I) and (B) NADH dehydrogenase subunit 6 (ND6). The levels of mtDNA were normalized to the internal control nuclear gene, glyceraldehyde 3-phosphate dehydrogenase. The values are expressed as a percentage of the sham-exposed control group and are presented as the mean \pm SD for three independent experiments. ${ }^{*} \mathrm{P}<0.05$ and ${ }^{* *} \mathrm{P}<0.01$ vs. sham-exposed control group; ${ }^{\#} \mathrm{P}<0.05$ and ${ }^{\# \#} \mathrm{P}<0.01$ vs. groups treated with $\mathrm{H}_{2} \mathrm{O}_{2}$ at the same concentration.

$\mathrm{H}_{2} \mathrm{O}_{2}$ for $8 \mathrm{~h}$, respectively, yielded marked decreases of the $\mathrm{red} / \mathrm{green}$ fluorescence ratio, to 71 and $59 \%$ of the control in the $\mathrm{H}_{2} \mathrm{O}_{2}$-treated MG63 cells, indicating that $\mathrm{H}_{2} \mathrm{O}_{2}$ induced depolarization of $\Delta \Psi \mathrm{m}$. By contrast, pretreatment of melatonin largely reversed the depolarization of $\Delta \Psi \mathrm{m}$ induced by $\mathrm{H}_{2} \mathrm{O}_{2}$ (Fig. 4).

Melatonin attenuates the reduction in mtDNA copy number in MG63 cells exposed to $\mathrm{H}_{2} \mathrm{O}_{2}$. To determine whether melatonin attenuates the reduction in mtDNA copy number observed in MG63 cells exposed to $\mathrm{H}_{2} \mathrm{O}_{2}$, two mitochondrial gene fragments, the COX I gene (representative of the mitochondrial heavy chain) and ND6 gene (representative of the mitochondrial light chain) were analyzed by qPCR. As shown in Fig. 5, $\mathrm{H}_{2} \mathrm{O}_{2}$ treatment significantly reduced the mtDNA copy number in MG63 cells; however, this reduction in mtDNA copy number was efficiently attenuated by pretreatment with melatonin.

\section{Discussion}

Osteoporosis is a bone disease that leads to an increased risk of fractures (1) and which has been recognized as a major threat to public health (2). It has been demonstrated that ROS-induced bone cell cytotoxicity is critical in the development of osteoporosis (4). Identification of an agent that protects bone cells from ROS-induced cytotoxicity may be a beneficial strategy in the prevention of osteoporosis. In the present study, it was demonstrated that $\mathrm{H}_{2} \mathrm{O}_{2}$ was cytotoxic to MG63 cells, as $\mathrm{H}_{2} \mathrm{O}_{2}$ reduced cell viability and increased $\mathrm{LDH}$ release in a dose- and time-dependent manner, within the range of concentrations used. We investigated whether $1 \mathrm{mM}$ melatonin prevented $\mathrm{H}_{2} \mathrm{O}_{2}$-induced toxicity, as melatonin exerts a protective effect against oxidative damage (26-28). As expected, melatonin pretreatment effectively prevented $\mathrm{H}_{2} \mathrm{O}_{2}$-induced cytotoxicity. Melatonin has been proposed to exert protective benefits by improving mitochondrial energetics and function (22-25). Therefore, melatonin may protect against $\mathrm{H}_{2} \mathrm{O}_{2}$-induced cytotoxicity by maintaining mitochondrial function.

ROS accumulation due to improper electron transport in the mitochondrial respiratory chain results in oxidative damage to biomacromolecules, including mitochondrial proteins and DNA, leading to lipid peroxidation, oxidation of amino acid residues and formation of protein-protein cross-links (29). These processes are important in the etiology of pathological conditions including osteoporosis (3). The ability of melatonin to protect against $\mathrm{H}_{2} \mathrm{O}_{2}$-induced intracellular oxygen species generation and oxidative damage in MG63 cells was also investigated. Following $\mathrm{H}_{2} \mathrm{O}_{2}$ treatment, the levels of intracellular ROS and lipid peroxidation (malondialdehyde, MDA) increased in MG63 osteoblastic cells. However, pretreatment with melatonin reduced $\mathrm{H}_{2} \mathrm{O}_{2}$-induced ROS generation and oxidative damage in MG63 cells. Melatonin directly increases the activity of complex I and IV of the electron transfer chain (30), which prevents ROS production and secondary oxidative damage. Additionally, melatonin induces the expression of genes encoded by mtDNA, which is essential for maintaining the activity of the respiratory chain (31). These results indicate that melatonin may act on respiratory chain complexes to promote mitochondrial homeostasis in $\mathrm{H}_{2} \mathrm{O}_{2}$-treated MG63 cells.

The beneficial effects of melatonin on mitochondrial function in $\mathrm{H}_{2} \mathrm{O}_{2}$-treated cells were demonstrated by the following results. Melatonin pretreatment prevented the reduction in ATP content induced by $\mathrm{H}_{2} \mathrm{O}_{2}$. Melatonin also directly increased the activity of complex I and IV of the electron transport chain. Therefore, melatonin may efficiently decrease $\mathrm{H}_{2} \mathrm{O}_{2}$-induced oxidative stress by improving the function of the electron transport chain and increasing ATP generation $(21,30)$. Melatonin also maintained $\Delta \Psi \mathrm{m}$ during exposure to $\mathrm{H}_{2} \mathrm{O}_{2}$ in MG63 cells. Melatonin interacts with the lipid bilayer and stabilizes the inner mitochondrial membrane, which is essential for maintaining $\Delta \Psi \mathrm{m}(21,30)$. This ability of melatonin to maintain $\Delta \Psi \mathrm{m}$ may be beneficial for improving mitochondrial oxidative phosphorylation and ATP generation under $\mathrm{H}_{2} \mathrm{O}_{2}$-induced oxidative stress $(21,32)$. In addition, melatonin prevented a reduction in mtDNA copy number in $\mathrm{H}_{2} \mathrm{O}_{2}$-treated MG63 cells. A reduction in mtDNA content amplifies oxidative stress by reducing the replication and transcription of mtDNA-encoded genes that are required for the respiratory chain (33). The ability of melatonin to stimulate the 
expression of mtDNA-encoded genes may protect the activity of the respiratory chain (31) and attenuate $\mathrm{H}_{2} \mathrm{O}_{2}$-induced cytotoxicity.

Due to its amphiphilic properties, melatonin freely accesses all compartments of the cell, and is able to become highly concentrated in the mitochondria (34), where it may exert direct beneficial effects. Furthermore, melatonin is administered in pharmacological doses without causing significant side-effects. Doses of $>1,200 \mathrm{mg} / \mathrm{kg}$ melatonin have been administered to humans without signs of toxicity and a median lethal dose $\left(\mathrm{LD}_{50}\right)$ has not been identified for melatonin (35). Therefore, the results of the present study and the validity and safety of melatonin in clinical applications suggests that melatonin is a potential therapeutic agent for preventing ROS-induced bone loss in diseases, such as osteoporosis.

In conclusion, mitochondrial dysfunction may underlie the cytotoxic effects of $\mathrm{H}_{2} \mathrm{O}_{2}$ in osteoblastic cells and melatonin may provide protective benefits through maintaining mitochondrial function in cells exposed to ROS. The beneficial effects of melatonin in the mitochondria may provide a novel strategy for protecting against ROS-induced bone cell cytotoxicity by improving mitochondrial function.

\section{Acknowledgements}

This study was partially supported by the National Natural Science Foundation of China (grant no. 81000803).

\section{References}

1. Sandhu SK and Hampson G: The pathogenesis, diagnosis, investigation and management of osteoporosis. J Clin Pathol 64: 1042-1050, 2011.

2. Choi EM: Magnolol protects osteoblastic MC3T3-E1 cells against antimycin A-induced cytotoxicity through activation of mitochondrial function. Inflammation 35: 1204-1212, 2012.

3. Xu ZS, Wang XY, Xiao DM, et al: Hydrogen sulfide protects MC3T3-E1 osteoblastic cells against $\mathrm{H}_{2} \mathrm{O}_{2}$-induced oxidative damage-implications for the treatment of osteoporosis. Free Radic Biol Med 50: 1314-1323, 2011.

4. Park BG, Yoo CI, Kim HT, Kwon CH and Kim YK: Role of mitogen-activated protein kinases in hydrogen peroxide-induced cell death in osteoblastic cells. Toxicology 215: 115-125, 2005.

5. Lee HC and Wei YH: Oxidative stress, mitochondrial DNA mutation, and apoptosis in aging. Exp Biol Med (Maywood) 232: 592-606, 2007.

6. Raha S and Robinson BH: Mitochondria, oxygen free radicals, disease and ageing. Trends Biochem Sci 25: 502-508, 2000.

7. ChoiEM:Deoxyacteinisolatedfrom Cimicifugaracemosa protects osteoblastic MC3T3-E1 cells against antimycin A-induced cytotoxicity. J Appl Toxicol 33: 488-494, 2013.

8. Slominski A, Fischer TW, Zmijewski MA, et al: On the role of melatonin in skin physiology and pathology. Endocrine 27: 137-148, 2005.

9. Bubenik GA: Gastrointestinal melatonin: localization, function, and clinical relevance. Dig Dis Sci 47: 2336-2348, 2002.

10. Jimenez-Jorge S, Jimenez-Caliani AJ, Guerrero JM, et al: Melatonin synthesis and melatonin-membrane receptor (MT1) expression during rat thymus development: role of the pineal gland. J Pineal Res 39: 77-83, 2005.

11. Rosenstein RE, Pandi-Perumal SR, Srinivasan V, Spence DW, Brown GM and Cardinali DP: Melatonin as a therapeutic tool in ophthalmology: implications for glaucoma and uveitis. J Pineal Res 49: 1-13, 2010.

12. Conti A, Conconi S, Hertens E, Skwarlo-Sonta K, Markowska M and Maestroni JM: Evidence for melatonin synthesis in mouse and human bone marrow cells. J Pineal Res 28: 193-202, 2000.
13. Rajaratnam SM, Middleton B, Stone BM, Arendt J and Dijk DJ: Melatonin advances the circadian timing of EEG sleep and directly facilitates sleep without altering its duration in extended sleep opportunities in humans. J Physiol 561: 339-351, 2004.

14. Arendt J and Skene DJ: Melatonin as a chronobiotic. Sleep Med Rev 9: 25-39, 2005.

15. Armstrong SM: Melatonin and circadian control in mammals. Experientia 45: 932-938, 1989.

16. Deacon S and Arendt J: Melatonin-induced temperature suppression and its acute phase-shifting effects correlate in a dose-dependent manner in humans. Brain Res 688: 77-85, 1995.

17. Srinivasan V, Spence WD, Pandi-Perumal SR, Zakharia R, Bhatnagar KP and Brzezinski A: Melatonin and human reproduction: shedding light on the darkness hormone. Gynecol Endocrinol 25: 779-785, 2009.

18. Guerrero JM and Reiter RJ: Melatonin-immune system relationships. Curr Top Med Chem 2: 167-179, 2002.

19. Hardeland R, Poeggeler B, Niebergall R and Zelosko V: Oxidation of melatonin by carbonate radicals and chemiluminescence emitted during pyrrole ring cleavage. J Pineal Res 34 : 17-25, 2003.

20. Coto-Montes A and Hardeland R: New vistas on oxidative damage and aging. Open Biol J 3: 39-52, 2010.

21. León J, Acuña-Castroviejo D, Escames G, Tan DX and Reiter RJ: Melatonin mitigates mitochondrial malfunction. J Pineal Res 38: $1-9,2005$.

22. Klongpanichapak S, Phansuwan-Pujito P, Ebadi M and Govitrapong P: Melatonin protects SK-N-SH neuroblastoma cells from amphetamine-induced neurotoxicity. J Pineal Res 43: 65-73, 2007.

23. Duan Q, Wang Z, Lu T, Chen J and Wang X: Comparison of 6-hydroxylmelatonin or melatonin in protecting neurons against ischemia/reperfusion-mediated injury. J Pineal Res 41: 351-357, 2006.

24. Herrera F, Martin V, Garcia-Santos G, Rodriguez-Blanco J, Antolin I and Rodriguez C: Melatonin prevents glutamateinduced oxytosis in the HT22 mouse hippocampal cell line through an antioxidant effect specifically targeting mitochondria. J Neurochem 100: 736-746, 2007.

25. Chen LJ, Gao YQ, Li XJ, Shen DH and Sun FY: Melatonin protects against MPTP/MPP ${ }^{+}$-induced mitochondrial DNA oxidative damage in vivo and in vitro. J Pineal Res 39: 34-42, 2005.

26. Jou MJ, Peng TI, Yu PZ, et al: Melatonin protects against common deletion of mitochondrial DNA-augmented mitochondrial oxidative stress and apoptosis. J Pineal Res 43: 389-403, 2007.

27. Tan DX, Manchester LC, Terron MP, Flores LJ and Reiter RJ: One molecule, many derivatives: a never-ending interaction of melatonin with reactive oxygen and nitrogen species? J Pineal Res 42: 28-42, 2007.

28. Reiter RJ, Tan DX, Jou MJ, Korkmaz A, Manchester LC and Paredes SD: Biogenic amines in the reduction of oxidative stress: melatonin and its metabolites. Neuro Endocrinol Lett 29: 391-398, 2008.

29. Choi EM, Kim GH and Lee YS: Diazoxide protects against hydrogen peroxide-induced toxicity in the osteoblastic MC3T3-E1 cells. Eur J Pharmacol 624: 45-50, 2009.

30. López A, García JA, Escames G, et al: Melatonin protects the mitochondria from oxidative damage reducing oxygen consumption, membrane potential, and superoxide anion production. J Pineal Res 46: 188-198, 2009.

31. Xu S, Zhong M, Zhang L, et al: Overexpression of Tfam protects mitochondria against beta-amyloid-induced oxidative damage in SH-SY5Y cells. FEBS J 276: 3800-3809, 2009.

32. Acuña Castroviejo D, Escames G, Carazo A, León J, Khaldy H and Reiter RJ: Melatonin, mitochondrial homeostasis and mitochondrial-related diseases. Curr Top Med Chem 2: 133-151, 2002.

33. Xu S, Zhou Z, Zhang L, et al: Exposure to $1800 \mathrm{MHz}$ radiofrequency radiation induces oxidative damage to mitochondrial DNA in primary cultured neurons. Brain Res 1311: 189-196, 2010.

34. Escames G, López A, García JA, et al: The role of mitochondria in brain aging and the effects of melatonin. Curr Neuropharmacol 8: $182-193,2010$.

35. Vairetti M, Ferrigno A, Bertone R, et al: Exogenous melatonin enhances bile flow and ATP levels after cold storage and reperfusion in rat liver: implications for liver transplantation. J Pineal Res 38: 223-230, 2005. 